\title{
In Memoriam of Edwin F. Beschler (1931-2018)
}

Thomas Hintermann (Director, EMS Publishing House)

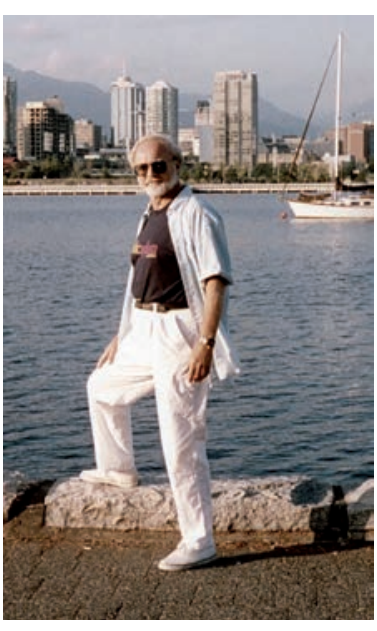

Edwin Beschler looking cool in front of the Vancouver skyline, 1993.
For almost 40 years, Edwin Beschler was one of the great figures of mathematical publishing. From 1961 until his move to Springer in 1989, he played a major role in the turbulent history of Academic Press, in varying positions from acquisitions editor in mathematics and related fields to president of the company. He himself wrote a highly interesting article on the origins and early days of this enterprise, arguably the most influential American publisher at that time [1]. Also noteworthy is his account of the foundation of the Journal of Combinatorial Theory, giving a lively and often amusing glimpse of the publishing processes in the 1960s [2]. From 1989 until his retirement in 1999, Edwin Beschler served as Executive Vice President and Editorial Director of Birkhäuser Boston, a subsidiary of Springer New York.

The first time I met Edwin was in Basel, in early 1990, shortly after becoming Mathematics Editor of Birkhäuser. At the time, Edwin Beschler was head of Birkhäuser Boston and he made the trip to Basel twice each year to attend the board of directors meetings. For the next 28 years, through our changing jobs and

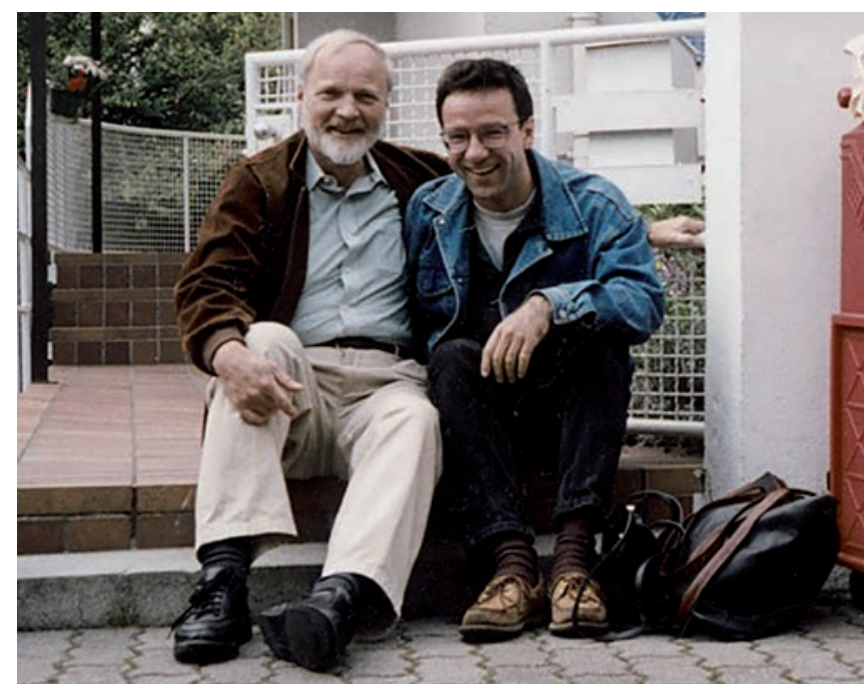

Edwin and T.H. on the road to the AMS-DMV Meeting in Heidelberg, 1993.

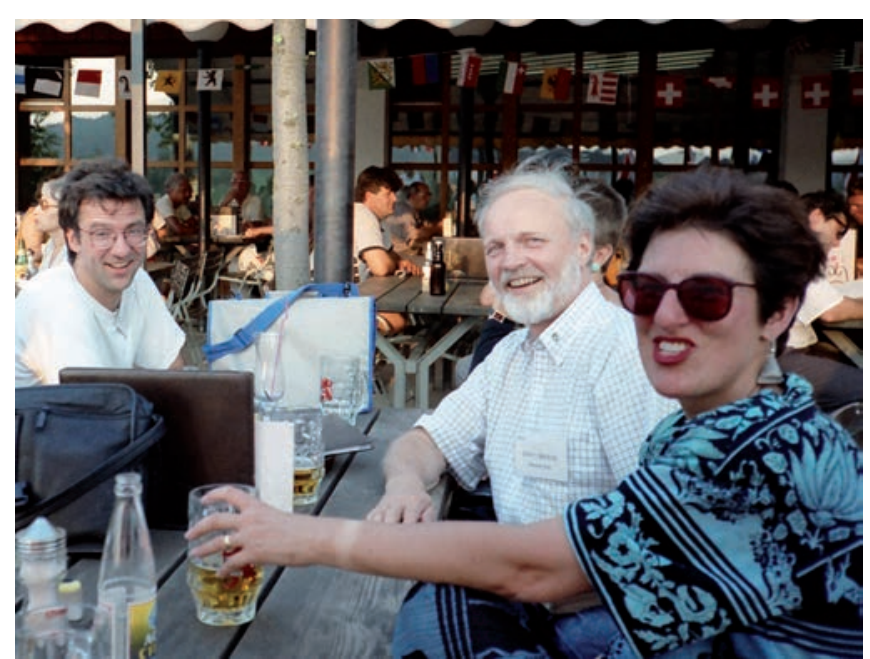

Fern and Edwin Beschler and T.H. during the ICM in Zürich, 1994. (All photos private collection Thomas Hintermann)

lives, we maintained a friendship even if our personal encounters remained rare. Professionally, Edwin was a great inspiration. While I was just a fledgling editor, he was looking back on a long and distinguished publishing career. His rich supply of anecdotes, insights and reminiscences provided an essential part of my education as a publisher. For years I collected letters written by Edwin which not only gave testimony to his superior linguistic style, but also his inimitable ways of putting even the most delicate and unpleasant messages into winsome words.

With Edwin a great figure of mathematical publishing, and an extraordinary man, has left us. A short obituary by Fern Beschler and Ina Mette appeared in the Notices of the AMS, Volume 65 (2018), number 6, p. 716.

\section{References}

[1] Edwin Beschler, The immigrants. Academic Press: Walter J. Johnson and Kurt Jacoby. Logos 18 (3), 153-166 (2007), Brill Academic Publishers.

[2] Edwin Beschler, Gian-Carlo Rota and the Founding of the Journal of Combinatorial Theory. Journal of Combinatorial Theory, Series A 91, 2-4 (2000). Academic Press. 